\title{
8
}
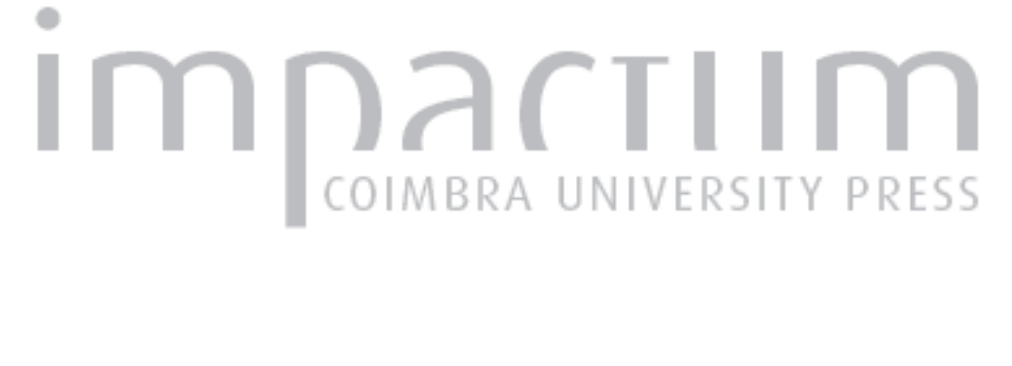

\section{Qualidade de vida, território e aprendizagem ao longo da vida na velhice} \author{
$\begin{array}{ll}\text { Autor(es): } & \text { Veiga, Márcia Regina Medeiros; Cordeiro, A. M. Rochette; Ferreira, }\end{array}$
}

Publicado por: Imprensa da Universidade de Coimbra

URL persistente:

URI:http://hdl.handle.net/10316.2/36902

DOI:

DOI:http://dx.doi.org/10.14195/0871-1623_33_21

Accessed : $\quad$ 26-Apr-2023 16:03:58

A navegação consulta e descarregamento dos títulos inseridos nas Bibliotecas Digitais UC Digitalis, UC Pombalina e UC Impactum, pressupõem a aceitação plena e sem reservas dos Termos e Condições de Uso destas Bibliotecas Digitais, disponíveis em https://digitalis.uc.pt/pt-pt/termos.

Conforme exposto nos referidos Termos e Condições de Uso, o descarregamento de títulos de acesso restrito requer uma licença válida de autorização devendo o utilizador aceder ao(s) documento(s) a partir de um endereço de IP da instituição detentora da supramencionada licença.

Ao utilizador é apenas permitido o descarregamento para uso pessoal, pelo que o emprego do(s) título(s) descarregado(s) para outro fim, designadamente comercial, carece de autorização do respetivo autor ou editor da obra.

Na medida em que todas as obras da UC Digitalis se encontram protegidas pelo Código do Direito de Autor e Direitos Conexos e demais legislação aplicável, toda a cópia, parcial ou total, deste documento, nos casos em que é legalmente admitida, deverá conter ou fazer-se acompanhar por este aviso.

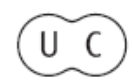




\section{Cadernos de Geografia}
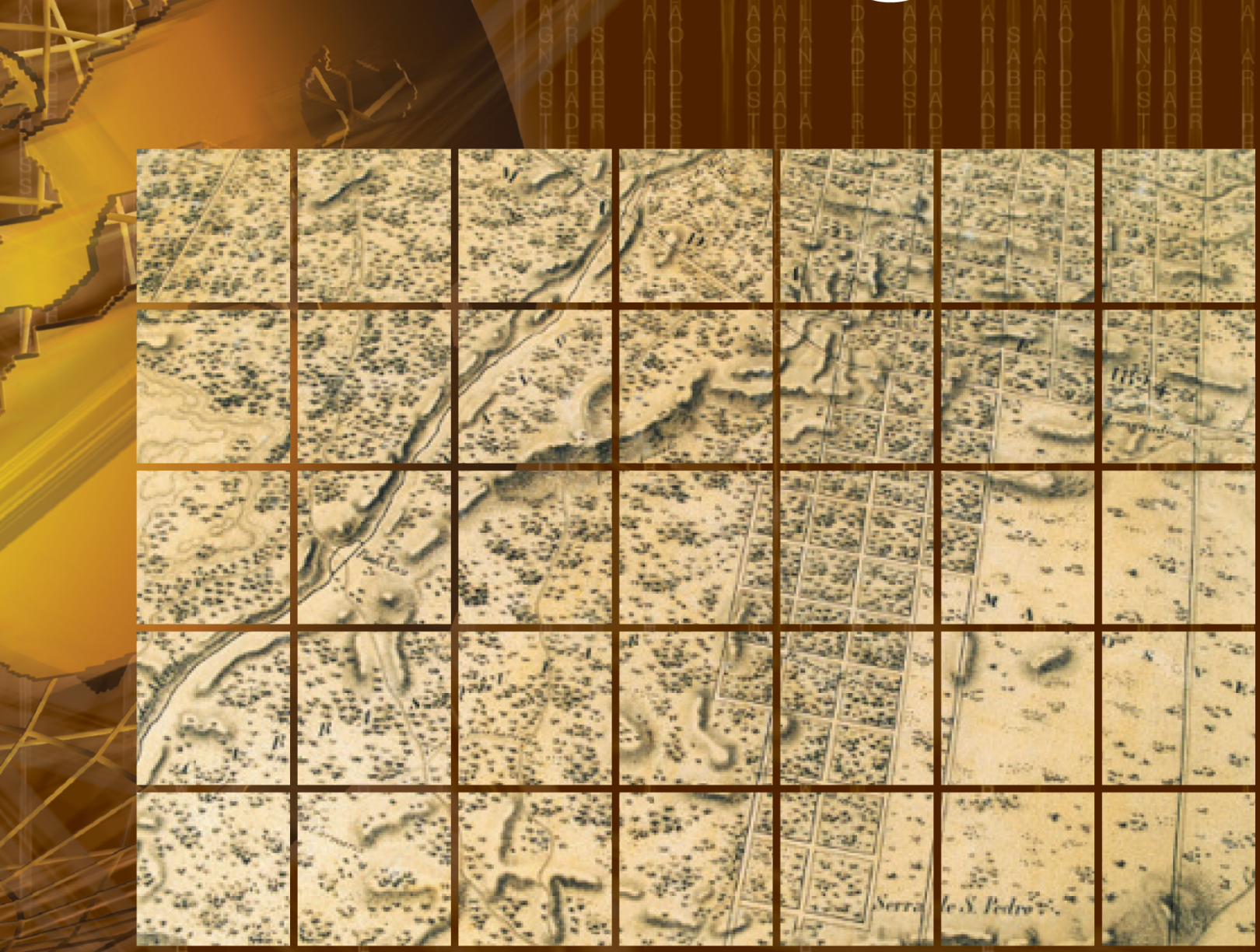

№ 33 - 2014

Imprensa da Universidade de Coimbra Faculdade de Letras | Universidade de Coimbra 


\title{
Qualidade de vida, território e aprendizagem ao longo da vida na velhice ${ }^{1}$ Quality of life, territory and lifelong learning in old age 1
}

\author{
Márcia Regina Medeiros Veiga \\ CEIS20, Universidade de Coimbra. \\ marciarmveiga@gmail.com
}

\author{
A. M. Rochette Cordeiro \\ Departamento de Geografia. Faculdade de Letras. Universidade de Coimbra. \\ rochettecordeiro@fl.uc.pt
}

\section{Sónia Mairos Ferreira}

Faculdade de Psicologia e Ciências da Educação- Universidade de Coimbra. smairosferreira@fpce.uc.pt

\section{Introdução}

Até que ponto a educação ao longo da vida, entendida como um projeto de vida, é percebida como elemento essencial no estabelecimento da qualidade de vida para sujeitos idosos? Mais ainda: em que medida o(s) território(s) é(são) definidor(es) na(s) perceção(ões) do que seja qualidade de vida para os idosos?

0 intuito deste trabalho não é meramente oferecer respostas objetivas e taxativas a estas questões, mas, a partir delas, delinear alguns subsídios, criando condições de fomento e abrindo novas possibilidades para um diálogo profícuo para uma velhice - ou, melhor dizendo, velhices - com qualidade. Assim, propomos uma reflexão teórica a partir da relação entre os quatro elementos convocados para este debate: qualidade de vida, aprendizagem ao longo da vida, projeto e território. Dessa forma, a primeira parte deste trabalho é dedicada à definição conceptual de cada um destes elementos, em separado. Em seguida, de posse desta conceptualização teoricamente referenciada, buscaremos, a partir do estabelecimento de uma relação dialógica entre os quatro elementos, respostas teóricas para esta temática integrada.

\section{Qualidade de vida na velhice}

O conceito de qualidade de vida não é dado a muitos consensos. Talvez o principal consenso a respeito deste conceito seja o de que as dificuldades na sua definição podem ser traduzidas por sua multidimensionalidade.

Entretanto, não obstante as dificuldades de seu significado, esta expressão tem sido usada de forma até extenuante, tanto por órgãos e instituições públicas ou privadas, como alguns observatórios sociais, preocupados em aferir os níveis de qualidade de vida de determinada população, a fim de

que se estabeleçam metas e objetivos concretos para sua positivação e potenciação, quanto pelo senso comum, que atribui aos próprios sujeitos, individualmente, a responsabilidade por uma vida com qualidade.

O que se sabe, no entanto, é que, talvez mesmo devido às dificuldades em defini-lo, o conceito de qualidade de vida tem sido revisto muitas vezes, nos últimos sessenta anos.

Em relação ao início do século, PASCHOAL (2000: 19-20) refere que a ideia de qualidade de vida surgiu no final da Segunda Grande Guerra, a partir do conceito de "boa vida", o qual se referia, estritamente, à conquista e acesso a bens materiais. Mais tarde, este conceito foi alargado, passando a representar o desenvolvimento económico (a partir de indicadores como o Produto Interno Bruto - PIB -, a renda per capita e as taxas de desemprego) e, posteriormente, social (com base em indicadores mais ampliados, como taxa de mortalidade infantil, esperança de vida, taxa de abandono escolar, nível de escolaridade, taxa de violência, saneamento básico) dos países ou dos diferentes territórios. Ainda segundo o mesmo autor (2000: 20), foi só a partir de 1960 que se sentiu a necessidade de se avaliar a qualidade de vida individual a partir das perceções dos próprios sujeitos sobre a sua própria qualidade de vida. A subjetividade, então, aliou-se aos elementos objetivos na avaliação da qualidade de vida.

O carácter subjetivo, somado aos múltiplos aspetos das configurações sociais (culturais, filosóficos, religiosos, históricos, geográficos), tem conferido à qualidade de vida uma multiplicidade de conceitos, dificultando, assim, as comparações entre as variadas realidades. Já anteriormente, alguns autores (BowLING, 1995; GRIMLEY-Evans, 1992) chegaram a criticar o uso da expressão, que consideraram inadequada em função de sua pouca objetividade e, consequentemente, praticidade.

Exageros à parte, entendemos que o estabelecimento de parâmetros mínimos de qualidade, a partir de critérios e indicadores objetivos, é neces-

\footnotetext{
Este trabalho corresponde à comunicação, com o mesmo título, apresentada no VIII Colóquio de Geografia de Coimbra, subordinado ao tema "Espaço, Natureza e Sociedade. A Geografia na Estratégia 2020 da Região Centro", realizado na Faculdade de Letras da Universidade de Coimbra, nos dias 27 e 28 de março de 2014 .
} 
sário para o desenvolvimento de políticas e serviços públicos em atendimento aos princípios básicos de equidade e de dignidade humana. É imprescindível, entretanto, que a subjetividade, expressa por diferenças culturais, regionais, religiosas, morais, entre outras, bem como pelas perceções dos próprios sujeitos, seja, de facto, levada em conta, na definição do que seja uma vida com qualidade.

Assumindo a qualidade de vida a partir de uma conceção eminentemente interdisciplinar, ALMEIDA et al. (2012: 13) a definem "como uma forma humana de perceção do próprio existir, a partir de esferas objetivas e subjetivas". Alertam, contudo, para o movimento e inter-relações constantes entre os diversos elementos que compõem estas esferas e para o reducionismo de certas visões, sobretudo as que colocam a qualidade de vida como sendo de responsabilidade individual, como algo que pode ser alcançado unicamente através da vontade e do esforço individual do sujeito no cultivo de hábitos e atitudes saudáveis. Segundo esses autores, este reducionismo se deve a uma "falta de especificidade terminológica e de uma visão fragmentada sobre o tema" (Almeida et al., 2012: 17).

Diante de uma diversidade de conceitos, derivada da multiplicidade de perspetivas disciplinares que envolvem a temática, reconhece-se que a qualidade de vida deva ser pautada por elementos objetivos e subjetivos. As perspetivas que privilegiam os elementos objetivos caracterizam a análise a partir de dados quantitativos e qualitativos que permitam traçar um perfil de um indivíduo ou grupo em relação ao seu acesso a bens e serviços, tais como alimentação, habitação, acesso à saúde, emprego, saneamento básico, segurança, educação, transporte. Em contrapartida, as perspetivas que destacam os elementos subjetivos como fundamentais na análise da qualidade de vida trabalham a partir de variáveis históricas, sociais, culturais e de interpretação individual sobre as condições de bens materiais e de serviços a que os sujeitos têm acesso ou não.

"Não busca uma caracterização dos níveis de vida apenas sobre dados objetivos; relaciona-os com fatores subjetivos e emocionais, expectativas e possibilidades dos indivíduos ou grupos em relação às suas realizações, e a perceção que os atores têm de suas próprias vidas, considerando, inclusive, questões imensuráveis como prazer, felicidade, angústia e tristeza."

(Almeida et al., 2012: 21).

Com o intuito de estabelecer critérios que possibilitassem a elaboração de um instrumento de avaliação sobre a qualidade de vida das variadas populações, privilegiando uma perspetiva transcultural e subjetiva, a Organização Mundial da Saúde criou um grupo formado por peritos pertencentes a 15 diferentes contextos culturais - o WHOQOL Group (World Health Organization Quality of Life) - a partir de um conceito de qualidade de vida que contempla a complexidade das relações entre saúde física e psicológica, nível de independência, relações sociais e crenças pessoais: "perceção do indivíduo sobre a sua posição na vida, dentro do contexto dos sistemas de cultura e valores nos quais está inserido e em relação aos seus objetivos, expectativas, padrões e preocupações" (World Health Organization) ${ }^{1}$.

Entendendo que, apesar de sua pluralidade e também a de seus sujeitos, a fase da velhice possa apresentar características próprias, o que possibilita que seja vista como uma categoria analítica, o WHOQOL Group desenvolveu um instrumento específico para avaliar a qualidade de vida dos/das idosos/as, o WHOQOL-OLD. Baseado em seis diferentes facetas (habilidades sensoriais; autonomia; atividades passadas, presentes e futuras; participação social; morte e morrer; e intimidade), o instrumento é composto por 24 questões e apresenta a recomendação de que deve ser aplicado juntamente com o instrumento abreviado (WHOQOL-BREF), complementando-o.

Apesar da complexidade que envolve sua definição, dificultando um trabalho mais objetivo, com resultados mais práticos e visíveis a um prazo não muito longo, o conceito de qualidade de vida é aqui chamado por entendermos que a maior esperança de $v_{i d a}{ }^{2}$, que tem acompanhado as populações em nível mundial, representando inegáveis ganhos para a humanidade, deve, ela própria, estar acompanhada de uma vida com qualidade. Por outras palavras, vive-se, geralmente, por mais tempo. Este tempo adicional, entretanto, não tem representado, necessariamente, um acréscimo - ou mesmo a manutenção - de qualidade na vida de grande parte da população mundial.

Assim, embora as dificuldades em se definir o que seja qualidade de vida em qualquer fase da vida, incluindo a velhice, infere-se que elementos directamente ligados ao território (participação social, autonomia e mobilidade, por exemplo) e ao projeto de vida (atividades futuras), questões também convocadas para este debate, sejam primordiais para essa definição.

\section{Aprendizagem ao longo da vida como projeto possível}

A aprendizagem ao longo da vida é um dos pontos da pauta europeia, tendo sido explicitada no Documento de Trabalho dos Serviços da Comissão das Comunidades Europeias de Outubro de 2000, intitulado "Memorando sobre Aprendizagem ao Longo da Vida", e figurando como uma das prioridades da "Estratégia Europa 2020".

0 primeiro documento define a aprendizagem ao longo da vida, a partir da "Estratégia Europeia de Emprego", "como toda e qualquer atividade de aprendiza-

\footnotetext{
${ }^{1} \mathrm{~A}$ partir de um primeiro instrumento, mais abrangente, contendo 100 questões, surgiram outros, dedicados a públicos ou áreas diferenciadas: um, abreviado, com 26 questões (WHOQOL-BREF); um dedicado aos portadores do vírus da SIDA (WHOQOL-HIV), com versões com 120, 37 e 31 questões; um dedicado às questões de espiritualidade, religiosidade e crenças pessoais (WHOQOL-SRBP) e, ainda, outro destinado aos idosos (WHOQOL-OLD) Fonte: WHO: http://www.who.int/mental_health/publications/whoqol/ en/. Acesso em 20 de Maio de 2014.

${ }^{2} \mathrm{Se}$, entre 1950 e 1955 a média de esperança de vida no mundo era de 46,6 anos, entre 2005 e 2010 esta esperança passou a ser de 67,6 anos. Embora este aumento seja desigual nas várias regiões do globo, pode-se dizer que ele é, mesmo, mundial, devendo aumentar ainda mais (Relatório sobre a Situação da População Mundial 2011 do Fundo de Populações das Nações Unidas. Disponível em: http://www.un.cv/files/PT-SWOP11 -WEB.pdf. Acesso em 30/05/2014).
} 
gem, com um objetivo, empreendida numa base contínua e visando melhorar conhecimentos, aptidões e competências" (Comissão das Comunidades EuROPEIAS, 2000: 3).

Embora a ênfase dada à aprendizagem ao longo da vida foque, prioritariamente, o fomento da empregabilidade, com base no paradigma do conhecimento $^{3}$, a Comissão Europeia reconhece na aprendizagem um potencializador do sentimento de pertença não só a um contexto profissional, mas também a um contexto social a partir do reconhecimento de outras formas de educação que não a formal ${ }^{4}$.

Assumimos, assim, que, quando se fala em aprendizagem ao longo da vida pensa-se em sujeitos idosos, pelo que a prioridade deve ser dada aos processos de educação não-formais e informais em detrimento de uma educação formal, condutora à obtenção de diplomas e ao reconhecimento de qualificações, com vistas ao mercado de trabalho. Esta última, contudo não pode ser desconsiderada, sob pena, também, de se estar alimentando preconceitos ao excluir do sistema de educação formal, a partir de critérios baseados unicamente na idade dos indivíduos, uma parte da população interessada em obter certificações, quer para a sua qualificação profissional, quer para sua satisfação pessoal ${ }^{5}$. Os processos de educação não-formal e informal, entretanto, valorizam os saberes e as diferenças individuais e culturais, promovendo, por isso, um ensinar/aprender a partir de uma relação dialógica e horizontal, onde a hierarquia e o controle, tão frequentes à educação formal, são suprimidos.

Nessa perspetiva, a aprendizagem ao longo da vida toma as dimensões, já mencionadas por Paulo Freire, de que somos - nós, seres humanos - seres incompletos, em constante desenvolvimento; desenvolvimento este que se dá através da aprendizagem: "o inacabamento do ser ou sua inconclusão é próprio da experiência vital. Onde há vida, há inacabamento" (1997: 55). A necessidade de aprender, de conhecer coisas novas a partir da comunicação, do

\footnotetext{
Este paradigma tem sido bastante questionado e criticado, pois tem promovido muito mais exclusão do que desenvolvimento social (SITOE, 2006).

4 A Comissão Europeia, através do "Memorando sobre Aprendizagem ao longo da Vida", distingue a educação formal como aquela que "decorre em instituições de ensino e formação e conduz a diplomas e qualificações reconhecidos"; educação não-formal como aquela que "decorre em paralelo aos sistemas de ensino e formação e não conduz, necessariamente, a certificados formais", podendo ocorrer no local de trabalho ou em outros espaços fora da escola formal e "ser ministrada através de organizações ou serviços criados em complemento aos sistemas convencionais (aulas de arte, música e desporto ou ensino privado de preparação para exames)"; e educação informal como "um acompanhamento natural da vida quotidiana. Contrariamente à aprendizagem formal e não-formal, este tipo de aprendizagem não é necessariamente intencional e, como tal, pode não ser reconhecida, mesmo pelos próprios indivíduos, como enriquecimento dos seus conhecimentos e aptidões" (CCE, 2000: 9).

${ }^{5}$ Chama-se idadismo, ou ageism, à discriminação etária baseada em crenças e estereótipos sobre o envelhecimento (LIMA, 2010: 23). Em Portugal, embora ainda pouco estudado, o idadismo tem se mostrado bastante presente. Segundo o relatório "Eubarómetro Especial de 2009", relativo à "Discrimination in UE in 2009", 53\% dos portugueses consideram a discriminação etária muito frequente no país. Na mesma direção, de acordo com o relatório do "European Social Survey", pesquisa também realizada em 2009, o idadismo é a principal forma de discriminação sentida pelos portugueses (17\%), seguida pela discriminação por sexo $(13 \%)$ e pela discriminação étnica (11\%) (MARQUES, 2011: 19).
}

diálogo, das trocas, é a prova de que a vida continua, ainda que já tenhamos chegado à velhice. É ainda Paulo Freire quem nos lembra:

“A educação tem sentido porque mulheres e homens aprenderam que é aprendendo que se fazem e se refazem, porque mulheres e homens se puderam assumir como seres capazes de saber, de saber que sabem, de saber que não sabem. De saber melhor o que já sabem, de saber que não sabem. A educação tem sentido porque, para serem, mulheres e homens precisam de estar sendo."

$$
\text { (FreIRE, 2000: 40). }
$$

Nesse sentido, também GadotTI (1981) entende a aprendizagem como um processo que se desenrola enquanto dura a vida, pressupondo o estabelecimento e/ou a continuidade de uma rede relacional. Aprender, então, é um processo relacional que implica, necessariamente, outro processo: o ensinar. Aprender/ensinar complementam-se, ainda, em mais outro processo, a educação. "A educação se apresenta, então, como uma situação de conhecimento e de intervenção do ser humano no mundo e uma forma de comunicação humana" (OLIVEIRA, 2009: 15). Através das redes de relações, nos tornamos seres aprendentes e seres ensinantes. Esta constatação é especialmente importante na velhice, devendo a solidariedade entre gerações partir deste pressuposto: os/as idosos/as, como qualquer ser humano em qualquer fase da vida, aprendem e também ensinam.

Aprendizagem ao longo da vida, nesse sentido, configura-se como parte de um projeto de vida. Não, necessariamente, um projeto em longo prazo, mas um projeto dentro de nossos "campos de possibilidades" (VeLHo, 2003). Projetar é expectar, é reconhecer-se como vivo e participativo dentro da comunidade; é ser, de certa forma, o condutor de sua própria vida.

0 conceito de aprendizagem ao longo da vida, aliado ao de projeto de vida, quando se estuda a velhice, é importante, pois ajuda-nos na compreensão das expectativas de vida dos sujeitos idosos, dos significados que atribuem à continuidade da vida e, por conseguinte, à própria velhice.

Nesse contexto, CaTÃo (2001) define projeto de vida como um movimento de transformação quotidiana a partir de condicionantes do passado e do presente em direção ao futuro. Nesse sentido, o projeto de vida se constitui na relação entre subjetividade $e$ objetividade, pois parte da análise das próprias experiências dos sujeitos que avaliam suas estratégias para a construção futura. Aliás, Gilberto Velho (VELHO, 2003: 8) vai nessa mesma direção, entendendo o projeto como "uma dimensão mais racional e consciente, com as circunstâncias expressas no campo de possibilidades, inarredável dimensão sociocultural (...). Nessa dialética os indivíduos se fazem, são constituídos, feitos e refeitos, através de suas trajetórias existenciais".

Sendo o projeto uma construção em que as dimensões individuais e subjetivas se relacionam, dialecticamente, com as dimensões colectivas socio- 
culturais, o território, com suas pluralidades dimensionais, relações e dinâmicas próprias, acaba por ser definidor dos "campos de possibilidades" a partir dos quais os projetos são construídos.

\section{O(s) território(s) como produtor(es) de velhice(s)}

A contemporaneidade globalizada assiste a um movimento que pode ser lido como um embaciamento temporal e espacial, levando alguns autores a defenderem abordagens como os "não-lugares" (AuGÉ, 2010) ou a "desterritorialização"6 (APpadural, 1996). Mesmo estes autores, entretanto, reconhecem que o espaço e o território são, sempre e necessariamente, levados em conta, ainda que se proponha um olhar mais relativizado, mais poroso e flexível nos estudos socioculturais.

Foucault (1984: 5) compreende esse movimento contemporâneo e considera que o espaço assume um papel de supremacia em relação ao tempo na organização do pensamento, entendendo o espaço contemporâneo como um "espaço de colocação", onde as relações de vizinhança, a retenção e a circulação de coisas e pessoas e o controlo sobre essas mesmas coisas e pessoas são elementos-chave na descrição e compreensão das sociedades e culturas.

Nessa direção, os espaços e territórios tornam-se um importante elemento de investigação, sendo entendidos como elementos relacionais que estabelecem, ao mesmo tempo, fronteiras geográficas e humanas (CoRrêA, 2000: 1). Dessa maneira, os territórios são palcos aonde diferentes relações de mobilidades/imobilidades, disputas, conquistas, afetos, solidariedades, vulnerabilidades/resistências, abandono/ocupação e pertencimento vão se estabelecer entre os diferentes atores. Em outras palavras, a análise das relações e dinâmicas que as pessoas neste caso específico, os/as idosos/as - estabelecem com os espaços em que vivem e pelos quais transitam - e vice-versa - e como estas relações são mediadas, difundidas e, muitas vezes, padronizadas e estereotipadas pelas várias instâncias e forças sociais é essencial para a compreensão das lógicas que se conjugam na produção de sentidos. As questões relativas à mobilidade, ocupação e pertencimento a um território são questões políticas (Foucault, 2008), sendo constitutivas da própria construção identitária - que não se faz sozinha, mas a partir de múltiplas e diferenciadas relações.

O território, como um delimitador geográfico e humano, campo importante das mais diversificadas relações, é, no nosso entendimento, um elemento

\footnotetext{
${ }^{6}$ Os geógrafos brasileiros Milton Santos e Rogério Haesbaert rejeitam fortemente o conceito de desterritorialização, que consideram um mito. SANTOS (1996) entende que o fenômeno da globalização tornou o território ainda mais importante, pois os espaços são cada vez mais diferenciados em função de suas capacidades frente à concentração de tecnologia informacional e comunicacional. Já Haesbaert convida a uma nova perspetiva: "( ) mais do que a perda ou o desaparecimento dos territórios, propomos discutir a complexidade dos processos de (re)territorialização em que estamos envolvidos, construindo territórios muito mais múltiplos ou, de forma mais adequada, tornando muito mais complexa nossa multiterritorialidade." (HAESBAERT, 2005: 6774)
}

fundamental para a compreensão do fenômeno da velhice e do envelhecimento.

No projeto de investigação doutoral de um dos autores, que está sendo desenvolvido no Concelho de Coimbra (região central de Portugal) em cinco territórios distintos - os setores urbanos de Celas, da Solum e da Alta (este último associado ao Centro Histórico de Coimbra) e as áreas com características rurais do Casal de Lobo (setor de baixa altitude e de geografia bastante plana) e do Botão (setor montanhoso), os dados preliminares dão conta de uma enorme diferenciação entre eles, tanto em termos geográfico-espaciais, quanto de tipologia e concentração populacional. Tendo como foco a velhice a partir das territorialidades e, consequentemente, dos territórios produzidos a partir desta relação, objetivando a construção de estratégias eficazes para a elaboração de diagnósticos sociais que correspondam às reais procuras das populações idosas, acreditamos que o levantamento cartográfico e etnográfico muito particularizado de cada um desses territórios, numa clara perspetiva interdisciplinar exigida por ambos os objetos - velhice e território - possibilite esta necessária lapidação do olhar às diversas realidades.

Neste trabalho, especificamente, a questão que se coloca é: até que ponto os territórios participam na construção do que se entende por qualidade de vida das populações idosas? 0 que queremos aqui problematizar é se - e como - os territórios e suas configurações espaciais (com possibilidades - ou não - de mobilidade e autonomia, com acesso - ou não - a bens e serviços) e relacionais (com os diferentes atores que constituem determinado território) inferem nas perceções que os/as idosos/as têm sobre a qualidade de suas próprias vidas e sobre a importância da aprendizagem ao longo da vida, enquanto um projeto para potencializar essa mesma qualidade.

\section{Aprendizagem ao longo da vida, projeto e território:} possibilidades dialógicas para uma velhice com qualidade

Historicamente, a velhice tem sido vista como uma fase da vida marcada por declínios biológicos, psicológicos e sociais, baixando, inevitável e consideravelmente, a qualidade de vida dos sujeitos. Por isso mesmo, as expectativas em torno de uma velhice com qualidade são, muitas vezes, bastante modestas $^{7}$.

De invisível - por sequer possuir estatuto social próprio, até o limiar do século XX, quando era confundida com mendicidade, deficiência, incapacidade e até vagabundagem e vadiagem - a identificável quando, a partir do início do século passado, o direito a uma reforma passa a ser institucionalizado e gene-

\footnotetext{
${ }^{7}$ Embora em grande parte das vezes, principalmente nos países em desenvolvimento, ou em países que passam por períodos de crises políticas económicas, como é o caso de Portugal na atualidade, as pessoas idosas ocupem um estatuto socioeconómico mais baixo, aumentando os riscos de precariedade, as incapacidades e até a morte (LimA, 2010: 25), os estudos sobre o bem-estar subjetivo têm apontado, paradoxalmente, uma realidade diversa, ao encontrarem um aumento do sentimento de bem-estar nas idades avançadas (LIMA, 2010: 109-110).
} 
ralizado, criando, assim, uma categoria social: a dos idosos -, a velhice quase sempre tem sido representada como vulnerável e dependente: primeiro, da família e, na falta desta, das instituições de solidariedade; em seguida, do Estado, com o estabelecimento de políticas públicas que, ainda hoje, buscam suprir as carências, o isolamento e a segregação a que os mais velhos parecem estar destinados (Fernandes, 1997).

Estas representações, muitas vezes reforçadas pelos próprios trabalhos académicos ${ }^{8}$, acabam por segregar ainda mais os sujeitos idosos, estigmatizando-os e despersonalizando-os. Vistos como uma categoria una, os idosos têm ignoradas suas individualidades e diferenças.

Embora as categorizações tenham, muitas vezes, o intuito do estabelecimento de direitos específicos a uma determinada categoria - os/as idosos/as, as mulheres, as crianças, os negros ou os indígenas, para citar alguns exemplos - a fim de acabar (ou, pelo menos, minimizar) com certas desigualdades sociais, há que se ter muito cuidado em não transformar os sujeitos em seres amorfos, sem identidade própria. No caso específico da velhice, FERNANDES (1997) alerta que um trabalho verdadeiramente sério e comprometido

“(...) exige começar por romper com as conceções dominantes do que é ser velho, procurando observar, por um lado, as distinções existentes entre diferentes categorias de agentes e, por outro, os contextos em que os fenómenos se desenvolvem, as representações que vão adquirindo forma e os problemas sociais que vão surgindo. É romper com a visão comum que tem a tendência de tratar uma categoria de idades como se fosse um grupo de agentes não diferenciados, dotados das mesmas propriedades substanciais, inscritas numa espécie de essência biológica, conhecidas e reconhecidas por todos, pois remetem para uma representação mental que lhes é comum."

(Fernandes, 1997: 13).

Esta necessária contextualização, de que nos fala a referida autora, diz respeito, entre outros contextos $^{9}$, ao território: onde vivem e por onde se movimentam os/as idosos/as - suas casas, suas ruas, seus bairros e arredores, os lugares que frequentam e as relações que estabelecem com e nestes espaços.

Como anteriormente mencionado, o território, enquanto espaço político e relacional, por sua vez, também é delineador dos "campos de possibilidades" (Velho, 2003, p. 8) de cada indivíduo, orientando suas

\footnotetext{
${ }^{8}$ Segundo Guita Grin Debert, os trabalhos académicos têm cristalizado ora uma imagem extremamente negativa da velhice, apontando apenas suas perdas, vulnerabilidades e incapacidades, ora, mais recentemente, uma imagem completamente inversa: a velhice como uma fase de liberação das amarras e compromissos sociais sendo, portanto, a "melhor idade" para se viver com plenitude e felicidade. Esta polaridade extrema acaba por não dar conta da multiplicidade e diversidade da experiência da velhice.

${ }^{9}$ Como os contextos social, económico, religioso e cultural, por exemplo.
}

escolhas e perspetivas a partir de uma realidade possível. Assim, infere-se ${ }^{10}$ que territórios hostis, de difícil acessibilidade e mobilidade, onde os mais velhos sentem-se isolados e segregados, impossibilitados de estabelecerem e manterem relações intergeracionais saudáveis e equânimes, onde o sentimento de pertença é substituído pela vulnerabilidade, insegurança e exclusão, só podem reduzir, sensivelmente, o campo de possibilidades dos/das idosos/ as, que tendem, também, a terem reduzidas suas expectativas e projecções para uma vida com qualidade. Por outro lado, territórios cujos espaços são transitáveis por todos com segurança, sem qualquer "armadilha"11, em que as relações sociais são pautadas na verdadeira solidariedade e no respeito entre as pessoas, seus ritmos e diferenças, com ofertas de serviços e produtos para todos, incluindo a população idosa, e proporcionando os encontros entre gerações, essas possibilidades, expectativas e projecções têm a tendência a aumentar.

Nesse sentido, a aprendizagem ao longo da vida, representando a possibilidade e a abertura para novos conhecimentos e/ou desenvolvimento de novas habilidades na continuidade da vida (GADOTTI, 1981; BrandÃo, 1982; FreIRE, 1997), passa a ser, realmente, muito significativa e enriquecedora.

0 que se deve aqui destacar é que a qualidade de vida das pessoas, especialmente das pessoas idosas, se encontra intrisecamente ligada às suas expectativas de vida, às suas capacidades de projetar o futuro que ainda têm pela frente, de estabelecer relações, trocas e aprendizagens contínuas.

0 território, por sua vez, é um dos elementos fundamentais no estabelecimento e na potencialização de campos de possibilidades, tanto mais diversos e significativos quanto os territórios forem amigáveis, acolhedores, acessíveis e inclusivos a todos e, especialmente, à população idosa.

\section{Considerações Finais}

No decorrer deste trabalho, procuramos estabelecer conexões entre território, aprendizagem ao longo da vida e projeto de vida na determinação de qualidade de vida para os sujeitos idosos.

0 território é aqui concebido como um espaço plural e multidimensional, ao mesmo tempo geográfico, social, histórico, cultural, político, relacional, dinámico e dialético. A velhice, por sua vez, também é entendida como uma categoria múltipla, que, para além da mera distinção etária, deve, da mesma forma que o território, ser tomada na pluralidade de

\footnotetext{
${ }^{10} \mathrm{~A}$ relação velhice-território é ainda muito pouco estudada, sendo o foco de nossa investigação doutoral, em desenvolvimento no Centro de Es tudos Interdisciplinares do Século XX, Instituto de Investigação Interdisciplinar, Universidade de Coimbra. Autores como Alexandre Kalache (2009), em sua observação sobre a necessidade do desenvolvimento de "cidades amigas dos idosos", ou García Canclini (1997), com seu estudo sobre a cidade do México, entretanto, permitem-nos tais inferéncias. ${ }^{11}$ Representada, por exemplo, por desníveis no terreno, humidade nas casas, inacessibilidade pedonal, trânsito inseguro, dificuldades de acesso (por distância ou outro motivo) aos serviços de saúde, farmácias, mercearias, espaços de convívio ou áreas verdes.
} 
dimensões que a compõem. Dessa maneira, partimos do pressuposto que o território é um elemento fundamental na constituição de velhices, ou seja, diferentes territórios produzem diferentes velhices.

A aprendizagem ao longo da vida, enquanto um projeto, uma prospeção futura, ainda que, no caso $\mathrm{dos} / \mathrm{das}$ idosos/as, este futuro possa estar bastante próximo, exigindo planos modestos, possíveis a curto e médio prazo, pode ser considerada como um fator essencial para uma vida com qualidade na velhice, uma vez que as expectativas revestem a vida de significados, independente do tempo efectivo que the resta. Por outras palavras, projetar o futuro, abrindo- se para novas relações e aprendizagens, quer de conhecimentos, quer de habilidades, é dar um sentido à própria vida, motivação necessária a qualquer pessoa, em qualquer idade, mas especialmente importante aos idosos, para os quais as perdas sentidas ao longo da vida e, muitas vezes, potencializadas na velhice, podem representar um grande desestímulo, levando, inclusive, à apatia, à dependência extrema e à depressão (American Psychological Association, s/d).

As possibilidades de projetar o futuro são dadas pelos contextos em que as pessoas se desenvolvem e se relacionam. Um destes contextos é o território, que pode, por um lado, potencializar uma velhice rica e com qualidade, ou, por outro, intensificar uma velhice vulnerável, dependente, solitária e triste, como, aliás, se começa a constatar através de alguns trabalhos já realizados no concelho de Coimbra.

Ainda que a qualidade de vida não prescinda de elementos subjetivos, que dependem tanto de componentes sociais e culturais, quanto das perspetivas de cada indivíduo, sabe-se que as relações e as interações sociais fundamentam uma vida com qualidade em qualquer idade. Particularmente na velhice, quando não é raro que as capacidades de mobilidade diminuam, diminuindo, também, os espaços de circulação das pessoas mais velhas, o território, principalmente o território onde os idosos residem, assume uma importância cabal na constituição de campos de possibilidades para uma vida com qualidade.

Finalmente, entendemos que a promoção de um diálogo e de uma reflexão em torno destes elementos (qualidade de vida, aprendizagem ao longo da vida, projeto e território) permite que pensemos em um projeto multi e interdisciplinar que possa, realmente, promover velhices ricas, ao mesmo tempo, em diversidade e em qualidade.

\section{Referências Bibliográficas}

Almeida, M. A. B. de; Gutierrez, G. L. e Marques, R. (2012) Qualidade de Vida: Definição, conceitos e interfaces com outras áreas de pesquisa. São Paulo, Escola de Artes, Ciências e Humanidades - EACH/USP.

American Psychological Association (s/d) - "Psychology and Aging - Addressing Mental Health Needs of Olders Adults". Acedido em Junho, 20, 2014, em http://www.apa. org/pi/aging/.
Appadural, A. (1996) - Modernity at large: cultural dimensions of globalization. Public Words, v. 1., University of Minnesota Press.

Augé, M. (2010) - Não Lugares - Introdução a uma antropologia da supermodernidade. $9^{\mathrm{a}}$ ed., Campinas, SP: Papirus.

Bowling, A. (1995) - "Health Related Quality of Life: a discussion of the concept, its use and measurement". In: Bowling, A. (Ed.) - Measuring Disease. A review of disease-specifc quality of life measurement scale. Buckingham, Philadelphia, Open University Press, pp. 1-19.

Brandão, C. R. (1982) - O que é educação. $5^{a}$ Ed. São Paulo, Brasiliense.

Catão, M. de F. F. M. (2001) - Projeto de vida em construção na exclusão/inserção social. João Pessoa, Editora Universitária.

Comissão das Comunidades Europelas (2000) - "Memorando sobre a Aprendizagem ao Longo da Vida", Documento de Trabalho dos Serviços da Comissão das Comunidades Europeias. Outubro de 2000.

CorrêA, R. L. (2000) - O espaço urbano. São Paulo, Editora Ática.

Debert, G. G. (1999) - “A construção e a reconstrução da velhice: família, classe social e etnicidade”. In: NeRI, A. L. e Debert, G. G. (orgs.) - Velhice e Sociedade. Campinas, Papirus, pp. 41-68.

Fernandes, A. A. (1997) - Velhice e Sociedade: Demografia, Família e Políticas Sociais em Portugal. Oeiras, Celta Editora.

Foucault, M. (1984) - "Of others spaces: utopias and heterotopias". Journal Architecture, Mouvement, Continuité (“Des Espace Autres,” March 1967 Translated from the French by Jay Miskowiec).

FoucAult, M. (2008) - Segurança, território, população: curso dado no Collège de France (1977-1978). Edição estabelecida por Michel Senellartsoba direção de Francois Ewald e Alessandro Fontana; tradução: Eduardo Brandão; revisão da tradução Claudia Berliner, Martins Fontes, São Paulo.

FreIRE, P. (1997) - Pedagogia da Autonomia: saberes necessários à prática educativa. São Paulo, Paz e Terra.

FreIRE, P. (2000) - Pedagogia da Indignação: cartas pedagógicas e outros escritos. São Paulo, UNESP.

Fundo de Populações das Nações Unidas (2011) - Relatório sobre a Situação da População Mundial. Acedido em Maio, 30, 2014, em: http://www.un.cv/files/PT-SWOP11. -WEB.pdf.

Gadotti, M. (1981) - A educação contra a educação: o esquecimento da educação e a educação permanente. Rio de Janeiro, Paz e Terra. 
García Canclini, N. (1997) - "Ciudades multiculturales y contradiciones de la modernización”. García CAnCLINI, N. Imaginarios Urbanos, Buenos Aires, Eudeba, pp. 67-106.

Grimley-Evans, J. (1992) - "Quality of Life assessments and elderly people”. Hopkins, A. (Ed.) - Measures of Quality of Life and the uses to which such measures may be put. Royal College of Physicians of London, pp. 107-16.

HaEsbaert, R. (2005) - “Da Desterritorialização à Multiterritorialidade”. Anais do X Encontro de Geógrafos da América Latina. Universidade de São Paulo, pp. 6774-6792. Acedido em Junho, 20, 2014, em http:// www. planificacion.geoamerica.org/textos/haesbaert_multi.pdf.

Kalache, A. (2009) - "O Envelhecimento e a Cidade". Revista O Tempo da Vida - Fórum Gulbenkian de Saúde sobre o Envelhecimento 2008/2009. Princípia, Cascais, pp. 213-229.

LimA, M. P. de (2010) - Envelhecimento (s). Colecção Estado da Arte. Coimbra, Imprensa da Universidade de Coimbra. MARQUES, S. (2011) - Discriminação da Terceira Idade. Colecção Ensaios da Fundação, Lisboa, Fundação Francisco Manuel dos Santos.
Oliveira, I. A. de (2009) - "Educação de Jovens, Adultos e Idosos: Aprendizagem ao Longo da Vida”. Revista Um Salto para o Futuro: Educação ao Longo da Vida. Ano $\mathrm{XIX}, \mathrm{n}^{\circ} 11$, pp. 14-19.

Organização Mundial da Saúde (2004) - WhOQOL-Old - Manual em Português.

Paschoal, S. M. P. (2000) - Qualidade de vida do idoso: elaboração de um instrumento que privilegia sua opinião. Dissertação de Mestrado, Faculdade de Medicina, Universidade de São Paulo, São Paulo. Acedido em Maio 5, 2014, em http: //www.teses.usp. br/teses/disponiveis/5/5137/tde-09112001-162639/.

Santos, M. (1996) - "O Retorno do Território". In: Santos, M.; SouzA, M. A. A. e Silveira, M. L. (orgs.) - Território: Globalização e Fragmentação. São Paulo, HUCITEC, $3^{\text {a }}$ ed., pp. 15-20.

Silvano, F. (2007) - Antropologia do Espaço: Uma introdução. Oeiras, Celta Editora.

Sitoe, R. M. (2006) - "Aprendizagem ao Longo da Vida: Um conceito utópico?”. Revista Comportamento Organizacional e Gestão. Vol. 12, n² 2, pp. 283-290.

VELHO, G. (2003) - Subjetividade e Sociedade: uma experiência de geração. $4^{\mathrm{a}}$ ed., Rio de Janeiro, Zahar Editores. 